\title{
Data Description and the Integrated Study of Ancient Near Eastern Works of Art: The Potential of Cylinder Seals
}

\author{
Alessandro di Ludovico*
}

... Roboti si všechno pamatují, ale nic víc.

Dokonce se ani nesmějí tomu, co lidé ríkají. ${ }^{1}$

KAREL ČAPE K, R.U.R. Rossum's Universal Robots (1920)

For several decades, the investigation of ancient Near Eastern cultures has needed to operate within a complex situation of modern conflicts and political instability. In some areas of great importance, such as Mesopotamia (situated in present-day Iraq and Syria), direct contact between scholars and archaeological sites and museums has been almost completely interrupted for decades, and the integrity of cultural heritage is now very precarious across Western Asia. Furthermore, since the beginning of the age of modern archaeological exploration in the region, both authorized excavations and (especially) illicit digs and the flourishing market for antiquities have led to the international dispersion of ancient artifacts into public and private collections. This removal of material products of ancient cultures from their regions of origin brings with it multiple complications affecting the work of the researcher. Most significantly, it limits the opportunity for a clear interpretation of the artifacts and the correct historiography of the civilizations to which they pertain. This is true in particular for most ancient Western Asiatic cultures, of which the largest part remained forgotten for many centuries, and a number

* The author of this contribution wants to express his gratitude to Sergio Camiz for all of his help and precious suggestions regarding computer applications and statistical algorithms, tools, and reasoning, which were necessary in carrying out the analyses.

1 "The robots remember everything, but that's all they do. They don't even laugh at what people tell them." (Translated from the original Czech by David Wyllie for Penguin's edition of the drama, London-New York, 2004).

(C) ALESSANDRo Di LUDOVICO, 2018 | DOI 10.1163/9789004375086_005

This is an open access chapter distributed under the terms of the prevailing CC-BY-NC License. 
are still very poorly known. The lack of continuity through the ages of a historical memory of these peoples, including testimony relating to most of their contacts with other cultures (especially Mediterranean Europe) and the transmission of their own traditions, puts the scholar at risk for very easy misunderstandings and involuntary prejudices. Visual language or written documents, for example, can frequently become sources for a large number of ambiguities and misinterpretations, since their contents can be seemingly familiar, but the comprehension of their contexts of origin, and especially of their relative cultural values, ${ }^{2}$ is very often insufficient.

The traditional art-historical approach finds in the artifacts themselves enough information that the loss of knowledge about their find contexts does not present a serious hurdle to their interpretation. One consequence of this approach is that interpretations that could seem obvious, evident, or taken for granted can hardly be incorporated with other evidence resulting from the same (or a closely related) context. Therefore, this paper advocates for the contextualized interpretation of materials, since the lives and possible meanings of ancient artifacts are very dynamic, and their interpretation is equally dynamic and complex.

\section{Approaching Artifacts}

In addition to find contexts (when such information is available), cross-comparison and experimental approaches open the way for new perspectives on ancient materials, including promising re-studies of long-known corpora. New studies of old corpora are needed especially when the material is of unknown or not homogeneously documented provenance. For those who are accustomed to the use of digital tools, it is not surprising that quantitative and computer-aided methods and procedures can play a central role in this research,

2 The issue of relative cultural values pertains to the proper contextualization of the values of symbols and concepts that are expressed through images or written words. The scholar needs to face not only the deciphering of their possible meanings and roles in the specific context of use, but also the factors that played a role in their production, perception, and interpretation in the original cultures. Furthermore, it is of great importance to locate the logical context in which such production and perception acted, since it is fundamental for the identification of the correct historical and cultural contexts in which these witnesses acted. For example, modes of communication related to an oral and rural context need to be considered according to general logical principles that are very different from those coming from official written sources (on this theme see, for example, Goody 1986). 
for which it is necessary to build and populate data archives and to develop strategies for cross-comparison and analysis.

The ideal following step would be to open the archives and share the data, but this still seems to be a chimeric goal, in particular because of an entrenched institutional and scholarly culture of keeping exclusive access to primary files. In this vein, a fairly pessimistic view was expressed many years ago by JeanClaude Gardin. ${ }^{3}$ Within the frame of the French school of analyse logiciste ${ }^{4}$ but considering theoretical developments at the international level (especially originating from Great Britain), ${ }^{5}$ already in the 1950s, Gardin outlined the basic principles for computerized systems that could automatically categorize artifacts and support quantitative studies. ${ }^{6}$ His research aimed to devise universal codes that could describe and represent with suitable precision any kind of archaeological material. Such codes were meant to be used on a large scale, would have permitted scholars to carry out comparisons quickly, and would have enabled the homogeneous publication and classification of materials.

The further ambition of Gardin was to extend this system so that it could translate the full content of excavation reports into a rigorously formalized language. ${ }^{7}$ This approach - largely inspired by linguistics - considered the importance of using a limited number of elements to describe all aspects of available information. ${ }^{8}$ His encoding systems were, of course, different, for each of his main categories of operations and artifacts (such as glyptic, pottery, and simple tools), but the final target was their universal application.

Within the field of Western Asiatic studies, Gardin's work was among the first long-term experiments on the application of quantitative and automated methods. His earliest tests used punch cards and computer machines, and the first concrete outcome of this methodology was the Répertoire analytique des cylindres orientaux,${ }^{9}$ a large open catalogue of cylinder seals. It was designed to overcome the problems of the dispersion and heterogeneous documentation (through diverse, isolated publications, mainly in journals) of this category of artifact by systematizing the seals' descriptions and therefore facilitating focused queries.

3 Gardin 1955, 107-115.

4 Analyse logiciste: an analytical procedure developed in France focusing on outlining and highlighting the symbolic elements (and their relevant functions) that can describe the structure of an observed phenomenon. The logicist procedure is also a critical review of the methodologies and the epistemological perspectives adopted by different scholars (Gardin 1997).

5 Moscati 2013, 9 .

6 Gardin 1958, 335-336; Gardin, 1967, 13.

7 Gardin 1958; Gardin 2002, 19-21.

8 Gardin 1966; Gardin 1967, 18-26.

9 Digard 1975. See also Gardin 1967, 21-26. 
It was only possible to produce the Répertoire with the generous collaboration of many French scholars who joined the initial efforts in collecting data on seals according to an established, uniform procedure. Gardin himself, however, foresaw that the project would never be enlarged, although it was widely appreciated by the scientific community. The basic hurdle for the future use and expansion of the catalogue, the value of which is evident from the methodological and practical points of view, was the unlikely availability of scholars willing to dedicate their own time and energies to a project that would not provide them with a personally fruitful outcome.

\section{The Peculiarities of Cylinder Seals}

Since Gardin, the field of ancient Near Eastern studies has pursued some encoding projects whose logics and structures were comparable to those of the Répertoire. The best-known project is the Cuneiform Digital Library Initiative (CDLI), which is still active, thanks both to the care of its coordinators and to modern technology..$^{10}$ Some other developments also followed the French logicist example, but they did not succeed in acquiring a large following and have all but fallen into oblivion.11

It is most notable, however, that in the field of quantitative applications to ancient Near Eastern visual languages, the majority of research has been dedicated to cylinder seals. ${ }^{12}$ It is therefore worth taking a look at the relevant features of these artifacts.

Cylinder seals have a number of features that give this class of artifacts a central role in the study of the pre-classic historical peoples of the Western Asiatic regions, since they are connected to the expressions of many different aspects of culture and social life. As far as we can currently understand, cylinder seals developed parallel to writing technologies in their earliest forms, and in later historical periods their use seems to have changed parallel to meaningful changes in writing systems and logics. ${ }^{13}$ Furthermore, cylinder seals not only had an official administrative use as guarantees for the reliability of docu-

10 CDLI: $<$ http://www.cdli.ucla.edu $>$ (accessed February 12, 2017). For further information on CDLI, see in this volume, Pagé-Perron, 198-200; Eraslan, 285-286.

11 For a short overview of the main experiments, see Ludovico and Camiz 2015a, 31; Ludovico 2016, 119-122.

12 Ludovico and Camiz 2015a, 29-32; Ludovico 2016, 118-122.

13 A research project related to this topic is currently being developed by the author of this chapter, but also see the relevant observations by Ross (2014). 
ments in the same way as a modern signature or a rubber stamp, but they also served as personal ornaments, amulets, and status symbols. ${ }^{14}$ Other remarkable features that can be attached to seals by inference are concerned with their peculiar materiality and intense relationship with the body of the owners or users. Seals usually bore their representations in a cyclical structure carved in the negative onto a curved surface in order to produce a continuous narrative when rolled onto a clay surface. The relationship of the seal with the iconography carved on its surface and that of both the cylinder and its iconography (and its replicated impressions) with the body of the person using it were thus probably complex and deserve to be part of the subject matter of the study of glyptic. The presence of cylinder seals in ancient daily life was based on their concrete materiality: on their colors, materials, and weight; on the manner in which they were worn and their possible roles as adornments; and on their concrete contact with the body of the person physically holding, carrying, or wearing them. ${ }^{15}$ With this in mind, the scholar should pay due attention to an implicit corollary warning deriving from what has been said here: the traditional laboratory seal impressions used to publish and study cylinder seals can reveal quite a lot of the iconographic aspects of these artifacts, but they are completely abstracted from the seal as a cultural and handcrafted product used in daily life, as well as in official and sacred contexts. Furthermore, the typically published "aseptic" modern representations of seals' carvings find few parallels in actual concrete ancient seal impressions, which were clearly carried out according to different logics and handling procedures than are used by today's archaeologists and museum curators. ${ }^{16}$ In other words, since modern illustrations and the "roll-outs" reflecting modern aesthetics that are photographed and displayed in galleries set aside the whole physicality of seals, except for practical information about a few features (such as dimensions and type of stone), most publications of cylinder seals are able neither to communicate, nor to pay the necessary attention to, a huge part of the potential information and qualities that these artifacts contain.

The need for alternative means of representing cylinder seals, voiced by Julia M. Asher-Greve and Willem B. Stern in the $1980 s,{ }^{17}$ and demonstrated in the more recent and very promising proposal by Martine de Vries-Melein and Paul

\footnotetext{
14 Cassin 1960; Collon 1987, 131-137; Haussperger 1991, 62-67; Porada 1993, 563; KlengelBrandt and Marzahn 1997, 229-230, pls. 16, 22-24; Nam 2008; Winter 2001. 
Boon for a low-cost optimized rendering and publication of cylinder seals, ${ }^{18}$ has been largely ignored by most scholars. The latter experiment is also particularly important because it raises an issue that is central to the application of digital methods in the humanities: first, the needs of scholars dealing with antiquities can be met by computer tools, which are subject to quick obsolescence, especially when these tools are designed with the contribution and feedback of the humanities' scientist. Second, the computer scientist cannot avoid taking into account quick and numerous updates in hardware and software systems. This makes each combined multi-disciplinary approach fleeting and so frustrates the need for a long-duration tool, such as an open catalogue. Such a catalogue, inspired by Gardin's early efforts, is fundamental if one considers the need for wide and homogeneous documentation, which would permit true comparisons and progressive enlargements of the datasets on different scales.

\section{Digital Humanities and the Study of Cylinder Seals: The Case of Presentation Scenes}

The cyber-approaches that will be introduced here began in response to the lack of comprehensive information provided by traditional catalogues of cylinder seals. In the course of some experiments I conducted on the iconography of a corpus of Mesopotamian cylinder seals dating from the Akkadian to the Ur III periods, ${ }^{19}$ I discovered just how little data primary sources usually provide about seals as physical objects. As has been mentioned, the iconographic content of cylinders tends to be shown in a modern abstract representation, omitting elements that would allow for the appreciation of the concrete relationships between images and the material structure of the artifact. Technical problems that complicate an ideal representation of seals in catalogues-especially printed ones - are many and can be well understood and justified, es-

18 Boon and de Vries-Melein 2009, <https://doi.org/10.17026/dans-x2d-cexg> (accessed April 25, 2017); 2013.

19 Ludovico 2005; 2008. There are still some uncertainties in defining the absolute chronology of the mentioned periods; however, following the Middle Chronology, they can be dated as follows: Akkadian period, c. 2340-2155 BCE; Post-Akkadian (or Early Ur III) period, c. 2155-2110 BCE; Ur III (or the Third Dynasty of Ur) period, c. 2110-2005 BCE. In this volume, for short philological and epigraphical observations concerning these periods, see Pagé-Perron, especially 196nı, and 201n32. The Ur III period is also known (mainly from the epigraphic and philological point of view) as the "Neo-Sumerian Period" (see in this volume, Nurmikko-Fuller, 349, 351). 
pecially because of the venerable age of some important and famous volumes. Today's primary publications of cylinder seals, however, still follow the original conventions, although they could certainly be more generous with their information, especially regarding the nature of the seals.

The investigation presented here is the continuation of my research on presentation scenes in Mesopotamian glyptic, which has been based, since its first approaches and tests, on linguistic logics. ${ }^{20}$ It is therefore fairly obvious that the most suitable means adopted for these inquiries should have a quantitative and digital nature, especially because of the need for finding correspondences and repetitions of combinations of minimal iconographic elements.

Different types of algorithms and data-mining strategies could match the approach and the theoretical background of this research well. ${ }^{21}$ For this reason, a number of applications were carried out in the past, in order both to test the models and to refine and adjust the encoding procedures. Some trials are of course necessary at the very beginning to oversee and check the full process and its phases, from encoding principles to outcomes, and to exert the necessary critical and self-critical assessments, but unforeseen responses or issues might emerge later, during the actual analysis. ${ }^{22}$ Furthermore, this way of con-

20 The first explanation of this is presented in Ludovico 2005. To summarize briefly: the scenes were subdivided into a number of minimal iconographic units, which, in the manner of the phonemes of a language, had no assumed meaning on their own, but rather built a meaning when they were combined with other basic units, forming a composition comparable to a visual sentence. In such a frame, the relative spatial relations of each basic iconographic unit in the field (in the manner of the relative position of letters in a written word) are of fundamental importance to encode and analyze the scenes. For these reasons, it is essential to consider the materiality of the seals and the fact that the field on which the scenes were carved is cylindrical.

The acquisition of information from a (usually) large dataset is also useful for additional purposes (such as a research path, a concrete application, etc.). Such a task can be accomplished through a large number of different types of algorithms and strategies. Typical of data mining is the search for correlations among features, like variables, within a certain dataset, so that the results of an investigation of that dataset can give clues to predict the figures related to those features in similar cases, or the possible development of some features in case some other features change in a certain way. Just as resources can be found and extracted from a mine through proper types of investigation and extraction techniques, useful information that was not evident at a first look can be extracted from a dataset through data-mining techniques.

Similar issues have been stressed in the research illustrated in this volume by Martino and Martino, 136-137. However, in the case of Martino and Martino, the different attempts aimed to adjust the algorithm, rather than the encoding, as it is the case here. 
sidering cylinder seals and their iconography has few, if any, precedents. As a result, the experimental phase of this research project was long.

\section{Algorithms and the Dataset}

The scenes have always been considered here as a complex message within which all components acquired their meaning mainly from their physical, syntactic connection with the others. Some issues were automatically raised by this approach, primarily the cyclical nature of the surface on which the representations were carved. As has been noted above, cylinder seals in three-dimensional space are much different from those on a plain surface. This issue is no small matter, since the people who produced and used such artifacts chiefly perceived their cylindrical materiality, not their abstract iconographic projections.

The encoding of the presentation scenes for the quantitative investigation was based on the subdivision of the cylindrical surface into areas organized through fixed reference points that were strictly related to the surface treatment at the moment in which the carving was planned. ${ }^{23}$ The "origin" of the scene, i.e., the area of the surface in which the presentation scene begins and ends, was then chosen as a reference point, together with the first figure of the scene. The first figure is identified as the one receiving the presentation and can be always identified without ambiguity. All elements composing the scene were thus described both for their nature and appearance and for their relative positions and spatial relationships to each other.

In the earliest steps, only basic statistical observations were recorded for a dataset collecting alphanumeric encodings of relatively heterogeneous presentation scene specimens from the Akkadian, Post-Akkadian, and Ur III periods (Fig. 3.1). ${ }^{24}$

The same corpus was then re-encoded into a presence/absence dataset in which the imagery was further split into smaller elementary units. ${ }^{25}$ This form fits much better for investigations with algorithms pertaining to the cat-

23 Ludovico 2005, 72-78; Ludovico and Ramazzotti 2008, 268-270; Ludovico 2011, 135-137; Ludovico, Camiz, and Pieri, 2013, 495-496; Ludovico and Camiz 2014, 9-13. For quantitative approaches applied to texts analysis, see in this volume, Bigot Juloux (162-163), PagéPerron (212, 216-217), Svärd, Jauhiainen, Sahala, and Lindén (226), and Monroe (257-259).

24 Ludovico 2005.

25 See in this volume, Martino and Martino (119) for a presence/absence dataset structured and designed according to the same logic. 

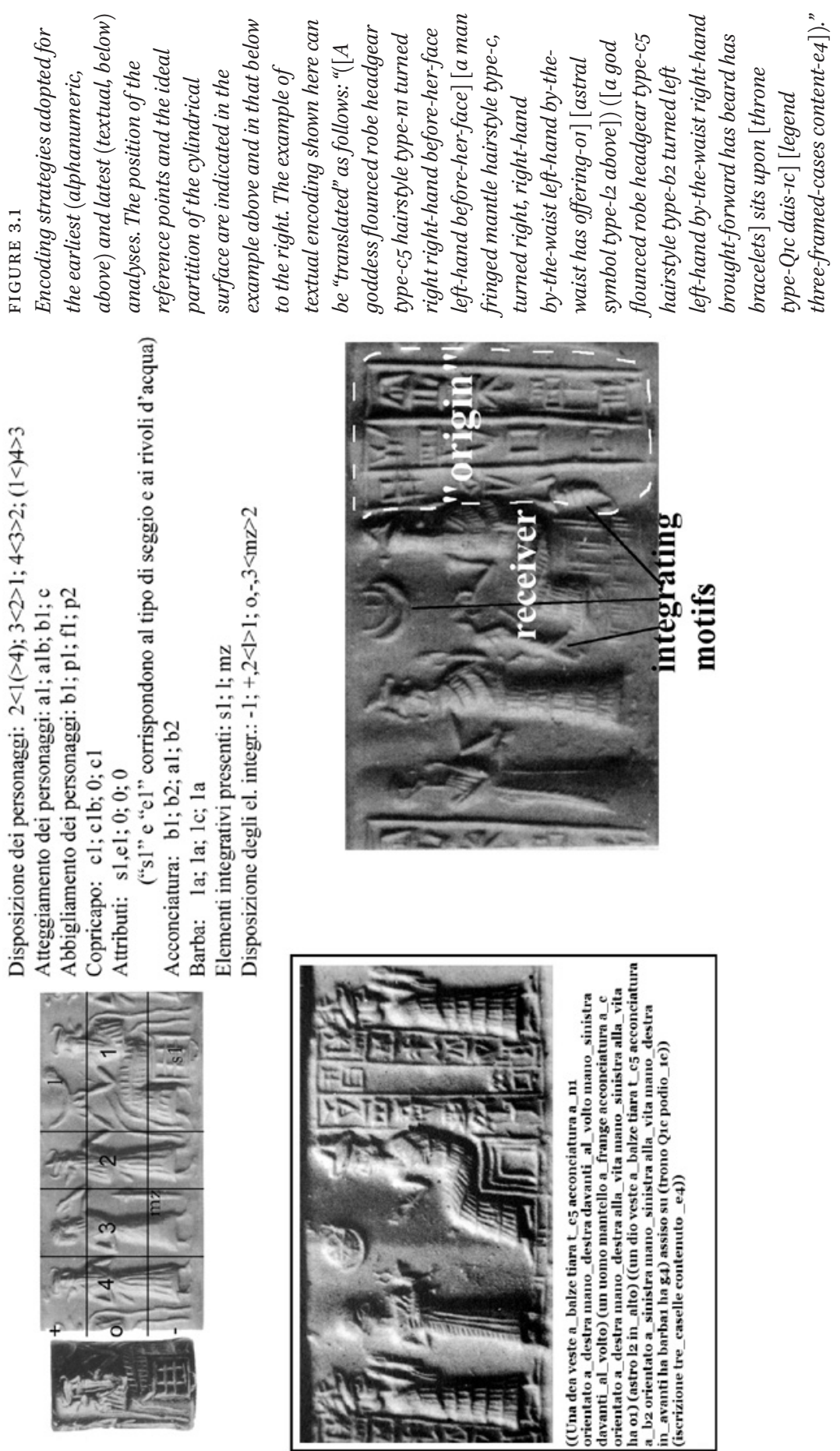
egory of Artificial Neural Networks (ANNs, such as Self-Organizing Maps and others), ${ }^{26}$ which allowed the establishment of scene classifications, interpretations concerning their logical connections, and an outline of their diachronic developments. ${ }^{27}$ A relatively simple algorithm even permitted the graphic representation of virtual scenes that correspond to the average figures of each class thus outlined. ${ }^{28}$

The following phase of this research, which is still in progress, is based on the use of statistical algorithms that were originally developed to investigate textual data (Fig. 3.1). They are primarily textual correspondence analysis and hierarchical classification algorithms. ${ }^{29}$ Compared to the ANNs, the latter

26 Artificial Neural Networks (ANNs) are a class of algorithms for which the design is inspired by the observation of the mechanisms of the human brain. One of the most interesting features of ANNS is their ability to learn, which implies an attitude to flexibility, and to adapt to specific situations and datasets. Self-Organizing Maps are a type of ANN devised by Teuvo Kohonen (1997); they have had great success and a number of concrete applications in many different fields. The logic underlying this type of ANN is the progressive distribution of data in an abstract map to form groups (potentially classes or subclasses), which can show, based on their measurable distances, the degree of similarity that has been recognized among them. Such a map is self-organizing, since it is built on the corpus of data; that is, the records of the dataset are observed and distributed on the map by the algorithm, so that their relative similarities build the map itself. The final map is thus the result of a progressive rearrangement of the abstract space and the group of records distributed throughout it. The abstract space is based on what the machine learns after each period (a "period" is a complete analysis of the whole dataset). The training phase, during which the machine learns the structure of the dataset, consists of a previously established number (often thousands) of periods. See also in this volume, ANNs applied a) to Archaeology, in Ramazzotti in particular, 64, 66-69; b) to Semantics, Svärd, Jauhiainen, Sahala, and Lindén, 229, 246.

27 Ludovico and Ramazzotti 2008; Ludovico 2011; Ludovico and Pieri 2011b; Ludovico, Camiz, and Pieri 2013.

28 Ludovico and Pieri 2011a. The map obtained through a Self-Organizing Map process shows groups of records that are more or less similar to each other. Besides the table of distances expressing the degree of similarity among groups, the algorithm also generates a chart for each group that represents a sort of average profile for it in terms of the composition of the average values calculated among the members of the group. The algorithm SEME, devised by Giovanni Pieri, can associate stylized iconographic basic units with the features (including the description of the relative position in the scene of each iconographic unit) that are well represented in the profile of a group, so that a group can be summarized and described graphically by an abstract presentation scene.

29 For the algorithms used here, see Lebart and Salem (1988); Lebart and Salem (1994). See also Camiz and Rova 2001; Camiz 2004; Ludovico and Camiz 2014. Correspondence analysis is a quantitative method used to describe a corpus of qualitative data. It falls within 
methods allow a clearer view of the entire mathematical process, giving the opportunity for complete control of the dynamics underlying the detection of similarites and differences. However, unlike ANNs, these techniques cannot work on extremely large datasets, and their outcomes suggest a smaller range of hypotheses useful for filling in gaps in cases of fragmentary documentation. The datasets that have been used so far in this research are, in any case, not vast and are still made up of reasonably well-preserved specimens. In addition, a further comparison between the two types of investigation (ANNs as well as textual correspondence analysis and hierarchical classification algorithms) confirmed that both systems give very interesting outcomes and can be used productively to complement one another. ${ }^{30}$

Approaches employing correspondence analysis have given sound preliminary results and proved that the corpus is fairly representative, which means that it is quite well suited to reflect the (much larger) whole original production of presentation scenes. ${ }^{31}$ At least in some experiments, the relationships of the different iconographic elements and their documented compositional strategies with the toponyms to which the scenes are referred left some doubts. These uncertainties were mainly due to the high number of specimens that cannot be connected with any places of origin. They were therefore given the toponym "Unknown."32 To verify these observations, the dataset was recently enlarged, adding only specimens of known origins, and then two identical correspondence analyses were carried out: the first on the whole corpus and the second on a subgroup from which scenes of unknown origin were removed.

the statistical realm of "factor methods" and can be described as the analysis of the dependent relationships existing among the different features of the observed data. When the data are collected in a table, for example, the rows can be referred to as the observed specimens (in this case the seals' scenes), while the columns refer to the different features (here, the different possible iconographic elements that appear in the scenes) that can pertain to the specimens. Correspondence analysis permits the investigation of the associations between the rows and columns of the table and enables associations to be displayed in a graphic form. Hierarchical classification is based on similarity and proximity. It classifies groups and shows hierarchical dependences among them. In the case mentioned here, a bottom-up approach was adopted, with records that were originally isolated and then progressively grouped, at higher levels, into larger groups.

30 Ludovico, Camiz, and Pieri 2013.

$31 \quad$ Ludovico and Camiz 2014; 2015b.

32 Ludovico and Camiz 2014; a more detailed study of this phenomenon is currently in preparation by the same authors. 
The whole corpus includes 425 specimens; of these, only 142 are of unknown origin, so the second analysis was carried out on a corpus of 283 verbal encodings of presentation scenes.

The geographic origins of these specimens are as follows (Table 3.1):33

TABLE 3.1 Corpus of specimens analyzed

\begin{tabular}{lc}
\hline Origin & Number of scenes \\
\hline Ur & 45 \\
Telloh & 43 \\
Susa & 43 \\
Umma & 75 \\
Lagaš & 35 \\
North-Bab & 26 \\
(Babylon+Nippur+Drehem+Sippar) & \\
South & 11 \\
(Failaka+Larsa+Adab+Uruk+Garšana) & \\
North-East & 5 \\
(Subartu+Ešnunna) & \\
Unknown & 142 \\
\hline
\end{tabular}

Although uneven, this distribution of specimens across different sites and regions has the potential to give a good general picture of the similarities and differences that exist among the iconographies used by different workshops or local administrations. In any case, there is another feature in the dataset that needs to be properly considered: the presence of a large number, although still a minority, of original seal impressions, which is also unequally distributed. This is a consequence of the historical accidents and circumstances that brought these artifacts to our knowledge. For instance, all examples from Umma and Lagaš are seal impressions, as demonstrated in Table 3.2, below. This may bring a potential imbalance to the analyses, but it can be controlled, since it can be followed through the analysis. It is, however, a means to investigate the possibility that at least two types of seals would have been distinguished through specific iconographic features or surface treatments: those

33 Here "geographic origin" means the settlement in which a seal was found or the area or site to which it can be attributed by inference. For the geographic location of Garšana, I have followed the suggestions of Heimpel (2011) and Steinkeller (2011). 
intended to be used on administrative documents and those designed for different uses or that had been deprived of their official value by the addition or erasing of visual elements. ${ }^{34}$

TABLE 3.2 Scenes from seals and impressions

\begin{tabular}{lcc}
\hline Origin & $\begin{array}{l}\text { Scenes from } \\
\text { seals }\end{array}$ & $\begin{array}{l}\text { Scenes from } \\
\text { impressions }\end{array}$ \\
\hline Ur & 39 & 6 \\
Telloh & 43 & 0 \\
Susa & 41 & 2 \\
Umma & 0 & 75 \\
Lagaš & 0 & 35 \\
North-Bab & 21 & 5 \\
(Babylon+Nippur+Drehem+Sippar) & & 2 \\
South & 9 & \\
(Failaka+Larsa+Adab+Uruk+Garšana) & & 0 \\
North-East & 5 & 2 \\
(Subartu+Ešnunna) & & \\
Unknown & 140 & \\
\hline
\end{tabular}

\section{The Procedure}

After being completed, the dataset made of the textual encodings of all 425 presentation scenes was imported into the SPAD 5.5 software package. ${ }^{35}$ SPAD

34 Examples of presentation scenes that have been meaningfully altered-probably to deprive the seal of its administrative function without affecting its other values—can be found in Collon (1982, no. 371 [BM 130707], no. 403 [BM 115418], no. 440 [BM 103232], and the like); exceptional examples of altered presentations that kept being used in the administrative sphere are shown in Fischer (1997, 100, Tf. 6, Abb. 1 [вм 13032A]; Tf. 7, Abb. 1 [BM 13080A]).

35 Lebart and Salem 1994. Système Portable pour l'Analyse des Données (SPAD) is a software for statistical analysis that has a Graphical User Interface (GUI) and includes a large series of different packages and functions. With the tools included in SPAD, one can perform different types of analyses and also manage data and whole datasets, with the aim, for example, of investigating their structure or preparing them to be processed. It is a proprietary software offering user interfaces in French. SPAD was first conceived as academic software, but after 1987 it became a commercial product developed by CISIA/DECISIA. The 


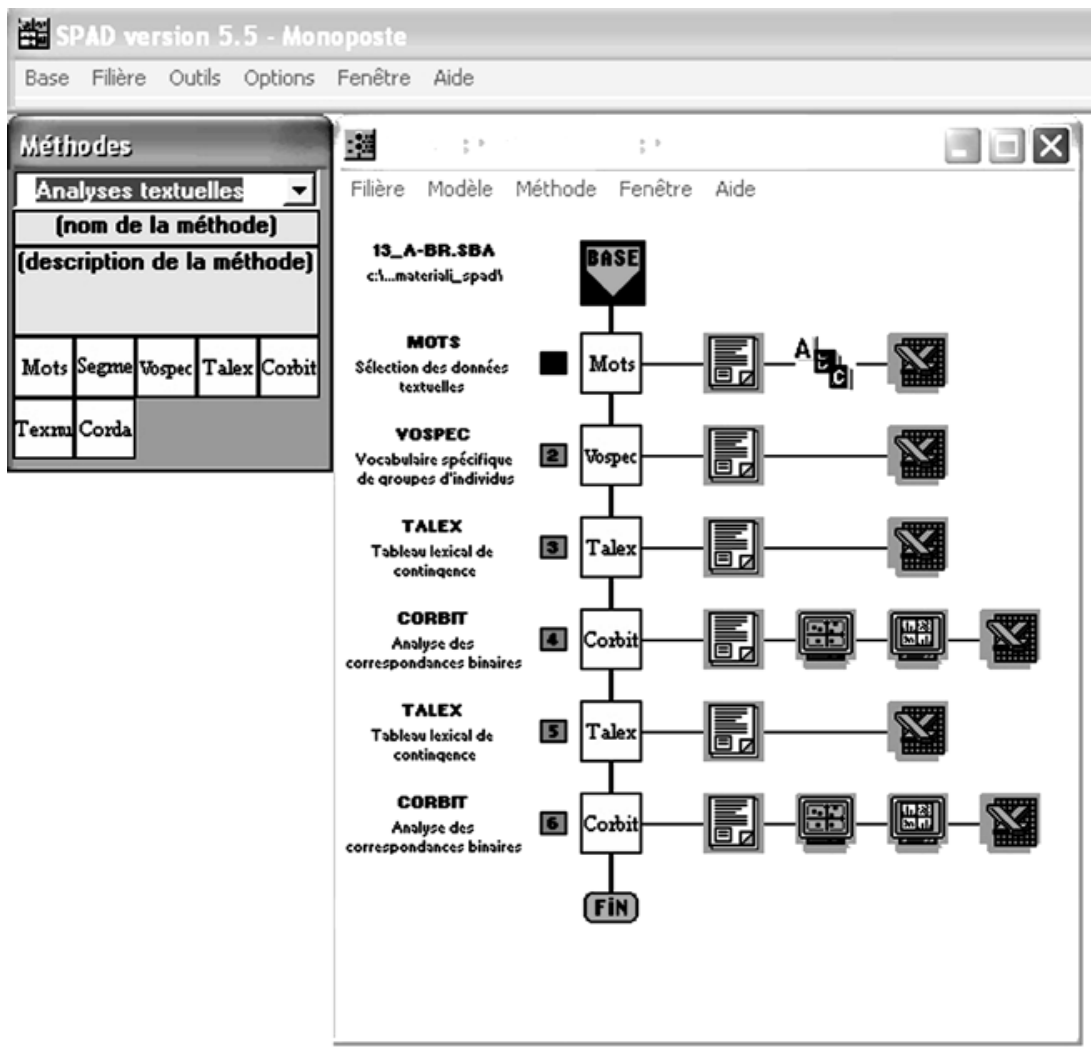

FIGURE 3.2 Procedure followed within SPAD 5.5. The boxes connected vertically represent the successive steps that have been followed, while those connected to them horizontally represent the relevant outcomes.

5.5 offers a large number of algorithms that can perform different types of statistical analyses; the ones used for this investigation belong to the category of textual analyses (analyses textuelles). The dataset thus needed to be specially prepared and adapted before being imported into SPAD. Since this software allows the researcher to develop each step of the analyses within a "chain" (filière), the data necessary for each step are directly available in the format required.

The chain used to perform this analysis was structured as follows (Fig. 3.2):

Step 1: Mots. The machine acquires the dataset and analyzes its structure. The vocabulary related to the dataset is drafted, together with the charts

version 5.5, used to perform the analyses discussed here, was released in 2002. For additional information regarding a GUI, see in this volume Eraslan $303 n 77$. 
concerning the frequency of each form (i.e., the word of the vocabulary), their lengths, and other criteria.

Step 2: Vospec. The machine drafts the vocabulary that is specific and typical of each group of specimens (or records), i.e., the forms that are especially related to each category, a category being identifiable through its connection with a specific variable. In this investigation, the places of origin have been chosen as variables to identify categories. Through an analogous process, the machine identifies the records that can be especially associated with a variable.

Step 3: Talex. The machine outlines the contingency table that shows the type of connection between the variables and the forms of the vocabulary. This is preparatory to the binary correspondence analysis.

Step 4: Corbit. The machine performs binary correspondence analysis. The outcome is a chart with the coordinates and the rate of participation of each variable and each form to the formation of the axes. These results are also represented in the form of a two-dimensional graph showing the position of the forms and the variables in relation to the axes, which are taken into account two by two.

The process was repeated for the dataset deprived of the specimens with unknown origin.

\section{Analyses}

The comparison between the outcomes of the binary correspondence immediately gave a clear representation of the impact caused by a meaningful presence of the records with unknown origin. As expected, the relative distances of toponyms are more easily readable along the main axes if each specimen has a

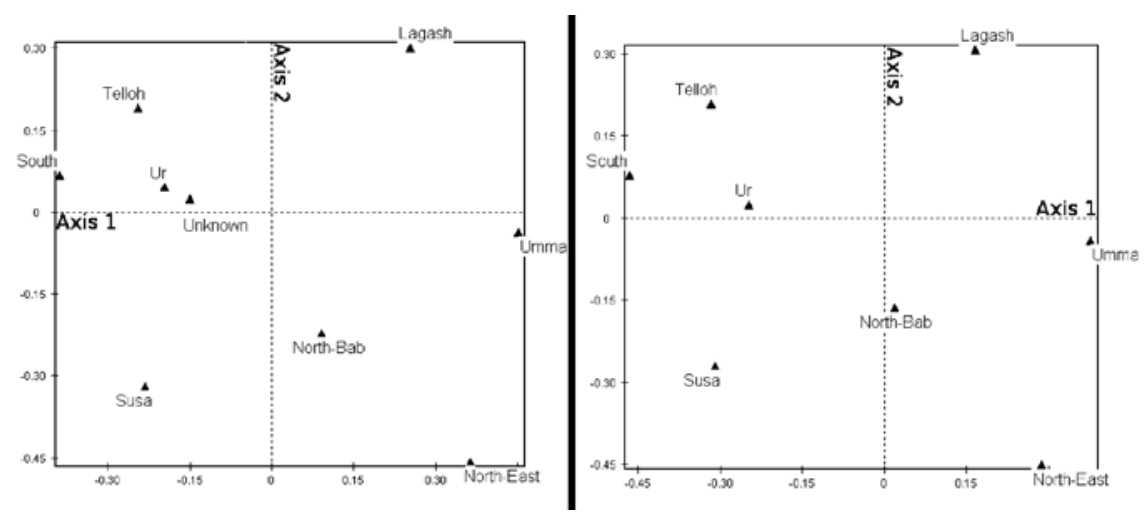

FIGURE 3.3 Graphs showing the outcomes of the binary correspondence analyses on the toponyms, with (left) and without (right) the specimens of unknown origins 
known origin. However, it also appears that the scenes of unknown origin do not cause a great change in the opposition and similarity relations among the other toponyms, although they do influence the general balance. This could mean that the uncontrolled mix of specimens classified as having an unknown origin is so heavily internally diversified that it represents an average of all types of scenes almost homogeneously. In the results of the analysis that excluded the scenes of unknown origin, the center of the graph is nevertheless more distant from Ur, Susa, and the southern sites along the first axis, which may mean that the relevant dataset is better balanced (Fig. 3.3).

The part of the analysis that focused on the vocabulary specific to the scenes from each toponym (see above, Step 2: Vospec) is essential for understanding in greater depth the similarity and opposition relations that are expressed by these graphs. Such typical vocabulary was filled out according to the criteria of being either typically present or typically absent. A $5 \%$ threshold was chosen to define the typicality. This means that a feature (expressed through an encoded element, that is, through a "word" or "form" used to describe formally the records of the dataset) was considered positively or negatively typical of the scenes from a toponym if there was a possibility of less than $5 \%$ that its presence (positively typical) or absence (negatively typical) in a specimen related to that toponym is random.

In short, the situation emerging from the analysis is the following (Table 3.3): The specific vocabulary suggests that a proper interpretation of the oppositions of toponyms along the axes would connect them with iconographic features that probably have to do with chronological differences (second axis), on the one hand, and with the treatment of the scenes, on the other hand (first axis). The two factors, represented here by the two axes, also have a partial direct relation with each other.

To be more specific without lingering over the smallest details, it is worth taking into account the amount and type of forms that the toponyms share in their typical vocabularies. The scenes from Ur, South, and Telloh have a tendency to show earlier iconographic elements in common, which recall those present in the very early Ur III (or post-Akkadian) presentation scenes. ${ }^{36} \mathrm{Com}$ paratively frequent in such a category of presentations are the female figures; some hairstyles that tend to disappear in later years (such as the one called here "woman's hairstyle with the hair gathered on the top back of the head"); and relatively simple thrones and divine headgear. Less present or totally absent are elements that can be connected to the presentation before a royal figure (such as the padded stool and the skull-cap), as well as personal ornaments 
Toponym Typical features

Positive Negative

Ur

presence of a goddess in the scene; presence of a crescent moon; plain robes; divine headgear with one or multiple pairs of horns; woman's hairstyle with the hair gathered on the top back of the head; simple framed throne; throne with central support and frame; simple dais under the throne; one-line legend; erased legend; legend containing a divine name

North-Bab arm depicted vertically, along the body; simple necklace; long end of necklace or robe falling along the back; little amphora; skull-cap; hairstyle with a hair gathered and going upwards; scorpion in the field; padded stool (royal); erased legend; legend's content not legible or erased; legend's content of the type ì-na-ba (gift-seal)

South presence of a woman; plain robes; headgear with one couple of horns; simple framed throne; two-lines framed legend; legend's content - type « $\mathrm{PN} 1$, son of PN2»

Telloh presence of a goddess in the scene; presence of a goddes; presence of a god; presence of a male character; a couple of presence of a male character; presence of characters hand in hand; plain robes; headgear with one pair of horns; characters who have material attributes; bearded character; character having simple hairstyle with double curl (female); or double bracelets; skull-cap; complex woman's hairstyle with the hair gathered headgear with multiple pairs of horns; on the top back of the head; woman's hairstyle with hair gathered by the neck hairstyle with the hair gathered in a long (male divine); little amphora; little cup; braid; mace in the field; simple square sun disc with a crescent moon in the field; throne; throne padded stool (royal) 
TABLE 3.3 Features of toponyms (cont.)

\section{Toponym Typical features}

Positive Negative

with central support and frame;

two-lines framed legend; legend's

content - type «PN1, wife of PN2»;

legend's content - type « $\mathrm{PN} 1$, son of $\mathrm{PN} 2$,

profession»; legend's content - type «PN,

profession»

North-East presence of a small goddess; presence of a couple of characters hand in hand characters who have material attributes;

divine headgear with multiple pairs of

horns; striped headgear; rod-and-ring;

sun disc with crescent moon in the field;

bird with long legs in the field; legend's

content not legible or erased

Susa plain robes; fringed robes; simple man's

hairstyle; striped headgear; small flat

presence of characters who have material headgear; simple "striped" man's attributes; bracelet; simple necklace; multiple necklaces; complex headgear headgear; woman's hairstyle with one big curl by the neck; standard with crescent in the field; crescent moon in the field; bird (goose) in the field; with multiple couples of horns; hairstyle with hair gathered by the neck (male divine); legend in 2 rows of framed lines; bird of prey with open wings; legend's monkey in the field; erased legend; simple framed throne; two-lines framed content - type « $\mathrm{PN} 1$, profession, son of legend; legend's content - type «PN1, son of $\mathrm{PN} 2 »$; legend's content - type «PN1, sevant of PN2»

Umma presence of a female character; bearded character; presence of male deity;

presence of women; presence of male presence of male figures; presence of figures; presence of goddesses; fringed robe; plain robe; divine headgear with one characters who have material attributes; skull-cap; complex headgear with or multiple pairs of horns; simple man's multiple pairs of horns; simple necklace; (female); woman's hairstyle with the hair multiple necklaces; little cup; bracelet; double bracelets; gathered on the top back of the head; elements placed in the field between two 
Toponym Typical features

Positive Negative

hairstyle with hair gathered by the neck characters; elements placed in the top part (male divine); standard with bull in the of the field; elements placed in the field in field; sun disc with crescent moon in the the middle; elements placed in the field, field; padded stool (royal); simple throne one above the other; bird of prey with with support; two-steps dais under the open wings in the field; crescent moon in throne; legend smaller than the height of the field; scorpion in the field; goose in the the field; three-lines framed legend; field;

legend in 2 rows of framed lines; legend's simple square throne; simple framed content - type «PN1, profession, son of throne; two-lines framed legend; legend's $\mathrm{PN} 2 »$; legend's content - type «RN, royal content - type «PN1, son of PN2, epithets, PN, his servant» profession»

Lagaš bird of prey with open wings; tree in the simple necklace; simple man's hairstyle; field; elements placed in the field in the plain robe; moon sickle in the field; middle; elements placed in the field, one two-lines framed legend; simple framed above the other; small vase in the field; throne; throne with central support and goose in the field; throne with multiple frame; profiles and multiple support; throne in the form of a dragon; throne with seat-back; dais under the throne and footstool; four-lines framed legend; legend in a row of framed lines; legend's content - type «PN1, profession, son of $\mathrm{PN} 2$, profession»; legend's content - type «RN, royal epithets, PN1, profession, son of PN2, his servant»

of the characters, male divine figures, and (typically later) complex types of divine headgear. On the opposite side of the first axis, Lagaš and Umma have much in common, with the former seemingly more isolated, but also richer in older or peculiar iconographies, such as the tree or the dragon-throne. The toponym "Umma" seems to be rather connected with male and royal characters and with elements that probably began to appear in the scenes sometime later, such as some body ornaments, while a reduced variety of the elements in the field is also observed. This general picture is made more complicated by 


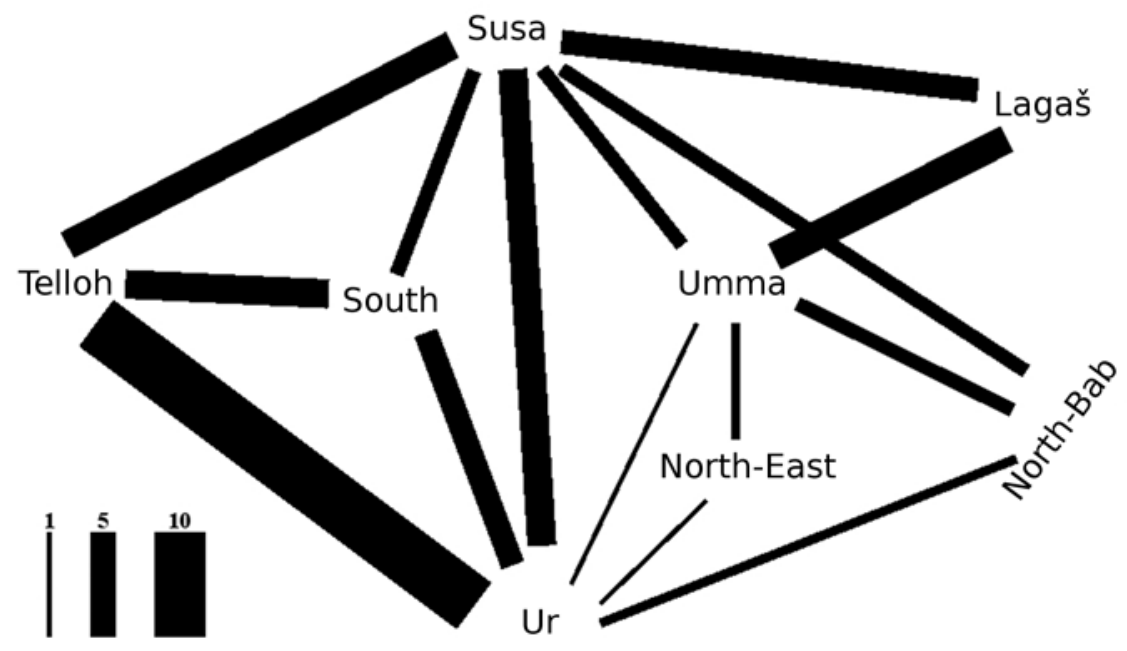

FIGURE 3.4 Total elements (forms) of the typical vocabulary that are shared by the different toponyms. Positive and negative forms have been considered together; the thickness of each edge is directly proportional to the total number of shared forms.

the relationship of the above-mentioned toponyms "Susa," "North-Bab," and "North-East," with their specific vocabulary. Such names of origin placed in the lower region of the graph seem to share some features (including changes in the iconography and in the legend, which often have been erased) that result from the activity of secondary carving. In particular, "North-East" is related to scenes containing the later addition of a small female deity in the field, with changes in the legend, or with combinations of archaic features with secondary ones. This may explain its peripheral position in the graph. Several ancient iconographic features are typical of the Susa corpus, which has many specific forms in common with the southern sites, such as fringed or plain robes and some hairstyles, but has also signs of re-worked legends. "North-Bab," placed in the middle-lower part of the graph, has in its typical vocabulary some features that express the presence of royal figures in the scene but also signal secondary changes (especially in the legend).

The overview of the shared vocabulary can be synthesized fairly simply (Fig. $3.4)$.

\section{Commentary}

A feature that emerges from this investigation is the remarkable difference between the scenes known from original-i.e., ancient—seal impressions and 
those recorded only from modern roll-outs of the cylinders. Furthermore, a number of cylinders were evidently re-carved during their time of use, and such secondary cuts quite probably affected the meaning of the whole representation, even when they were not particularly showy.

The two toponyms, Umma and Lagaš, that are only related to original impressions, are separated in the graph by a meaningful distance. This clearly means, if one looks at their typical vocabulary, that the specimens from Lagaš are more varied and show iconographic features typical of an earlier tradition (such as some plain robes, the small vase, or the tree in the field) and, probably, of the symbolic language of the specific site. Umma's vocabulary converges with that of Lagaš, especially in the field of the seals' legends (shape and content) and in the absence of elements (such as the crescent moon being represented alone) that began to appear in earlier phases. A distinctive feature for Lagaš is the bird of prey, usually represented with open wings in the top part of the field; this is an element that is, on the contrary, typically absent at Umma. The latter toponym is rather explicitly connected with forms that describe the presentations before a royal figure (for instance, the padded stool).

At the other end of axis 1, the toponyms share a typical vocabulary that tends to exclude royal features and incorporate female figures; typical earlier features here especially include the women's hairstyles and the plain robes. As far as the shape and content of the legends is concerned, the difference among the toponyms placed by the positive side of the same axis is evident. In Telloh, Ur, and South, they are usually shorter and with little information, and sometimes they are erased. This should have a relationship with the administrative role of the seal. As has emerged from earlier research, ${ }^{37}$ the shape, structure, and dimensions of some categories of Ur III administrative documents seem to have progressively changed in tandem with the dimensions and type of the legends of the seals used on them.

Finally, North-East, North-Bab, and Susa seem in particular to be related to the negative part of axis 2, with elements that are characteristic of later phases (such as the rod-and-ring) or of re-cuts (such as the small goddess). It is probably meaningful that Susa's typical vocabulary contains forms that represent legends that are structurally similar to those of Ur, Telloh, and South.

Correspondence analysis seems to provide very clear outcomes in the investigation of the iconography of late third-millennium BCE presentation scenes in glyptic. The characterization of the traits that are typical of the different toponyms is unambiguously revealed. These results highlight some issues that are closely connected to further aspects: besides purely iconographic features, it is 
worth taking into account more concrete ones, such as the specific function for which the seal was designed. Indeed, the life of a cylinder seal may have been quite short or very long, and its use may have changed. These changes were mirrored by the (primary and/or secondary) treatment of the seals' surfaces. A next step for this investigation, therefore, should be the enlargement of the dataset, or rather the creation of a completely new dataset containing only original seal impressions of known origin, and with the specification of the type of document on which they were impressed. This phase is currently under development, but it will probably be complicated because of the lack of truly shared data (in the sense of open archives) regarding original seal impressions. The latter are rather difficult to study if one has not had the chance to get into direct physical contact with the object, since they are rarely published, and, when they are, it is usually in formats that do not indicate their physical and iconographic features.

Another issue that deserves to be considered is the research on the different possible compositional structures of the presentation scenes and their main parts. Another correspondence analysis algorithm that has been tested on presentation scenes in recent years can focus on identifying structures and substructures of the scenes' description. ${ }^{38}$ This step will be carried out again in the near future after a suitable adaptation of the dataset.

\section{References}

Asher-Greve, Julia M., and Willem B. Stern. 1983. "A New Analytical Method and its Applications to Cylinder Seals." Iraq 45: 157-162.

Asher-Greve, Julia M., and Willem B. Stern. 1986. "Practical Advices for Collecting Data on Cylinder Seals." Akkadica 49: 17-19.

Bahrani, Zainab. 2014. The Infinite Image: Art, Time and the Aesthetic Dimension in Antiquity. London: Reaktion Books.

Boon, Paul, and Martine de Vries-Melein. 2009. Mesopotamian Cylinder Seals:Description andPhotographs of Five Sealsfrom the NINO Collection. DANs. <https://doi.org/10.17026/ dans-x2d-cexg>.

Boon, Paul, and Martine de Vries-Melein. 2013. "Cylinder Seals Revealed." In Fusion of Cultures. Proceedings of the 38 th Annual Conference on Computer Applications and Quantitative Methods in Archaeology, Granada, April 6-9 2010, edited by Francisco Contreras, Mercedes Farjas, and Francisco J. Melero, 511-517. BAR-IS 2494. Oxford: Archaeopress.

$3^{8} \quad$ Ludovico and Camiz 2015b. 
Camiz, Sergio. 2004. "On the Coding of Archaeological Data." Acalc 15: 201-218.

Camiz, Sergio, and Elena Rova. 2001. "Exploratory Analyses of Structured Images: A Test on Different Coding Procedures and Analysis Methods." Acalc 12: 7-45.

Cassin, Elena. 196o. "Le sceau: un fait de civilisation dans la Mésopotamie ancienne." Annales. Economies, Sociétés, Civilisations 4: 742-751.

Collon, Dominique. 1982. Catalogue of the Western Asiatic Seals in the British Museum. Cylinder Seals II. Akkadian, Post Akkadian, Ur III Periods. London: The British Museum.

Collon, Dominique. 1987. First Impressions: Cylinder Seals in the Ancient Near East. London: The British Museum.

Collon, Dominique. 2001. "How Seals Were Worn and Carried: The Archaeological and Iconographical Evidence." In Proceedings of the XLVe RAI:Part II: Yale University: Seals and Seal Impressions, edited by William W. Hallo and Irene J. Winter, 15-30. Bethesda, MD: CDL Press.

Digard, François, ed. 1975. Répertoire analytique des cylindres orientaux publiés dans des sources bibliographiques éparses (sur ordinateur). Paris: Centre National de la Recherche Scientifique.

Fischer, Claudia. 1997. "Siegelabrollungen im British Museum auf Ur III-zeitlichen Texten aus der Provinz Lagaš." BaM 28: 97-183.

Gardin, Jean-Claude. 1955. "Problèmes de la documentation." Diogène 11: 107-124.

Gardin, Jean-Claude. 1958. "Four Codes for the Description of Artifacts: An Essay in Archeological Technique and Theory." AmA 60 (2): 335-357.

Gardin, Jean-Claude. 1966. "Éléments d'un modèle pour la description des lexiques documentaires." Bulletin des bibliothèques de France 5: 171-182.

Gardin, Jean-Claude. 1967. "Methods for the Descriptive Analysis of Archeological Material." AmAnt 32: 13-30.

Gardin, Jean-Claude. 1997. "Le questionnement logiciste et les conflits d'interprétation." Enquête, anthropologie, histoire, sociologie 5: 35-54.

Gardin, Jean-Claude. 2002. "Les modèles logico-discursif en Archéologie." Acalc 13: 19-30.

Goody, Jack. 1986. The Logic of Writing and the Organization of Society. Cambridge: Cambridge University Press.

Haussperger, Martha. 1991. Die Einführungsszene. Entwicklung eines mesopotamischen Motivs von der altakkadischen bis zum Ende der altbabylonischen Zeit. Münchener Vorderasiatiche Studien 9. München-Wien: Profil.

Heimpel, Wolfgang. 2011. "On the Location of the Forests of Garšana." In Garšana Studies, edited by David I. Owen, 153-159. CusAs 6. Bethesda, MD: CDL Press.

Klengel-Brandt, Evelyn, and Joachim Marzahn. 1997. "Ein Hortfund mit Kreuzen aus Assur." BaM 28: 209-238.

Kohonen, Teuvo. 1997. Self-Organizing Maps. New York: Springer. 
Lebart, Ludovic, and André Salem. 1988. Analyse statistique des données textuelles. Paris: Dunod.

Lebart, Ludovic, and André Salem. 1994. Statistique textuelle. Paris: Dunod.

Ludovico, Alessandro di. 2005. "Scene-in-frammenti: una proposta di analisi delle 'scene di presentazione' dei sigilli a cilindro mesopotamici orientata all'elaborazione statistica ed informatica dei dati." In Studi in onore di Paolo Matthiae presentati in occasione del suo sessantacinquesimo compleanno, CMAO X-Special Issue, edited by Alessandro di Ludovico and Davide Nadali, 57-95. Rome: Sapienza University Press.

Ludovico, Alessandro di. 2008. "Between Akkad and Ur III: Observations on a 'Short Century' from the Point of View of Glyptic." In Proceedings of the 4th International Congress on the Archaeology of the Ancient Near East 29 March - 3 April 2004, Freie Universität Berlin, Vol. 1, edited by Hartmut Kühne, Rainer M. Czichon, and Florian J. Kreppner, 321-341. Wiesbaden: Harrassowitz.

Ludovico, Alessandro di. 2010. "La glittica della fine del Terzo Millennio e il sentimento di immortalità del potere in Mesopotamia." In Quale Oriente? Omaggio a un Maestro. Studi di Arte e di Archeologia del Vicino Oriente in memoria di A. Moortgat a trenta anni dalla sua morte, edited by Rita Dolce, 241-261. Palermo: Flaccovio.

Ludovico, Alessandro di. 2011. "Experimental Approaches to Glyptic Art Using Artificial Neural Networks: An Investigation into the Ur III Iconological Context." In On the Road to Reconstructing the Past. Proceedings of the 36 th International Conference on Computer Applications and Quantitative Methods in Archaeology (CAA), Budapest, April 2-6, 2008, edited by Erzsébet Jerem, Redő Ferenc, and Vajk Szeverényi, 135-146. Budapest: Archaeolingua.

Ludovico, Alessandro di. 2012. "The Uses of the Cylinder Seal as Clues of Mental Structuring Processes inside Ur III State Machinery." In Organization, Representation, and Symbols of Power in the Ancient Near East. Proceedings of the 54th Rencontre Assyriologique Internationale at Würzburg 20-25July 2008, edited by Gernot Wilhelm, 275-289. Winona Lake, IN: Eisenbrauns.

Ludovico, Alessandro di. 2013. "Symbols and Bureaucratic Performances in Ur III Administrative Sphere: An Interpretation through Data Mining." In From the 21st Century B.C. to the 21st Century A.D. Proceedings of the International Conference on Sumerian Studies Held in Madrid, 22-24 July 2010, edited by Steven J. Garfinkle and Manuel Molina, 125-151. Winona Lake, IN: Eisenbrauns.

Ludovico, Alessandro di. 2016. "L'uso dei metodi quantitativi nell'indagine sui linguaggi figurativi del Vicino Oriente preclassico: Una disamina globale.” In (Digital) Humanities: nuovi strumenti per vecchi problemi (Sette casi di studio), edited by Simone Celani, 114-124. Status Quaestionis 10. Rome: Sapienza University Press.

Ludovico, Alessandro di, and Sergio Camiz. 2014. "A Quantitative Approach to Ur III Mesopotamian Figurative Languages: Reflections, Results, and New Proposals." Acalc 25: 7-32. 
Ludovico, Alessandro di, and Sergio Camiz. 2015a. "Art History of the Ancient Near East and Mathematical Models: An Overview." In 2rst century Archeaology: Concepts, Methods and Tools. Proceedings of the 42nd Annual Conference on Computer Applications and Quantitative Methods in Archaeology, Paris, April 22nd-25th 2014, edited by François Giligny, François Djindjian, Laurent Costa, Paola Moscati, and Sandrine Robert, 29-34. Oxford: Archaeopress.

Ludovico, Alessandro di, and Sergio Camiz. 2015b. "Ancient Mesopotamian Glyptic Products, Statistics and Data Mining: A Research Proposal." In 21stcentury Archeaology. Concepts, Methods and Tools. Proceedings of the 42nd Annual Conference on Computer Applications and Quantitative Methods in Archaeology, Paris, April 22nd - 25th 2014, edited by François Giligny, François Djindjian, Laurent Costa, Paola Moscati, and Sandrine Robert, 489-496. Oxford: Archaeopress.

Ludovico, Alessandro di, Sergio Camiz, and Giovanni Pieri. 2013. "Comparative Use of Mathematical Models in an Investigation on Mesopotamian Cylinder Seals." In Fusion of Cultures. Proceedings of the 38 th Annual Conference on Computer Applications and Quantitative Methods in Archaeology, Granada, April 6-9 2010, edited by Francisco Contreras, Mercedes Farjas, and Francisco J. Melero, 495-498. BAR-IS 2494. Oxford: Archaeopress.

Ludovico, Alessandro di, and Giovanni Pieri. 2011a. "How to Facilitate Interpretation of Natural Computation Results by Converting Binary Codes of Images back to Images." CiiT International Journal of Artificial Intelligent Systems and Machine Learning 3 (7): 437-446.

Ludovico, Alessandro di, and Giovanni Pieri. 2011b. "Artificial Neural Networks and Ancient Artifacts: Justifications for a Multiform Integrated Approach Using PST and Auto-CM Models." Acalc 22: 99-128.

Ludovico, Alessandro di, and Marco Ramazzotti. 2008. "Reconstructing Lexicography in Glyptic Art: Structural Relations between the Akkadian Age and the Ur III Period." In Proceedings of the 5ist Rencontre Assyriologique Internationale, Held at the Oriental Institute of the University of Chicago, July 18-22 2005, edited by Robert D. Biggs, Jennie Myers, and Martha T. Roth, 263-280. SAOc 62. Chicago: The Oriental Institute of the Universtiy of Chicago.

Moscati, Paola. 2013. "Jean-Claude Gardin (Parigi 1925-2013). Dalla meccanografia all'informatica archeologica." Acalc 24: 7-24.

Nam, Roger S. 2008. "A Different Kind of Impression:The Decorative Aspects of Cylinder Seals in Ugarit." UF 40: 523-531.

Porada, Edith. 1993. "Why Cylinder Seals? Engraved Cylindrical Seal Stones of the Ancient Near East, Fourth to First Millennium B.c." The Art Bulletin 75: 563-582.

Ross, Jennifer C. 2014. "Art's Role in the Origins of Writing: The Seal Carver, the Scribe, and the Earliest Lexical Texts." In Critical Approaches in Ancient Near Eastern Art, edited by Brian A. Brown and Marian H. Feldman, 295-317. Berlin: De Gruyter. 
Steinkeller, Piotr. 2011. "On the Location of the Town of GARšana and Related Matters." In Garšana Studies, edited by David I. Owen, 373-390. CUSAs 6. Bethesda, MD: CDL Press.

Winter, Irene J. 2001. "Introduction: Glyptic, History, and Historiography." In Proceedings of the XLVe RAI: Part II: Yale University: Seals and Seal Impressions, edited by William W. Hallo, and Irene J. Winter, 1-14. Bethesda, MD: CDL Press. 